\title{
ETAG certified rockfall barriers - new design approach according to UNI 11211:4/2012
}

\author{
M Cerro Maccaferri Asia, Malaysia \\ G Giacchetti Officine Maccaferri, Italy \\ M Lelli Maccaferri Asia, Malaysia
}

A Grimod France Maccaferri, France

A Arul Maccaferri Asia, Malaysia

\begin{abstract}
European Technical Approval Guideline (ETAG) 027 ensures that a tested falling rock protection kit (interception structure, support structure and connection elements) is able to withstand a series of impacts for a fixed energy level. The main manufacturers of flexible rockfall barriers have tested and certified their products in compliance with this guideline. To take into account the differences between the field tests, which are carried out in controlled state, and the real conditions in situ, a new guideline was developed in January 2012 by the Italian Organization for Standardization, Ente Nazionale di Unificazione (UNI), named UNI 11211-4:2012. The purpose of this guideline is to ensure a high level of safety for the structures protected by the flexible rockfall barriers considering all the possible uncertainties that are normally found during the design process (height of the bounce, mass of the rock, velocity etc.). The calculation methodology suggested by the UNI 11211-4:2012 is the well-known limit state design approach. The purpose of this paper is to present the differences between tests and real in situ conditions, and to introduce the new design approach proposed by the UNI 11211:4/2012. Some practical aspects on the installation of the rockfall barriers that need to be considered during the design stage will also be highlighted.
\end{abstract}

\section{Introduction}

Rockfall barriers are commonly used to provide rockfall protection along roads, railways, in open pit mines, for infrastructure, and jobsites to protect the labour. They are classified as passive mitigation systems because they do not affect the source area, but they arrest the rock masses trajectories or reduce their falling velocity and energy. Passive mitigation systems include also debris flow barriers, embankments and hybrid fences.

According to the European Guideline ETAG 027 (EOTA 2008) rockfall barriers may be grouped in two categories: rigid barrier, with a capacity lower than $100 \mathrm{~kJ}$, and deformable barrier, with a capacity higher than $100 \mathrm{~kJ}$. At the time of writing, the maximum capacity of a deformable rockfall barrier was $8,600 \mathrm{~kJ}$, 27 tons travelling at $90 \mathrm{~km} / \mathrm{h}$. For higher energies, rockfall embankments are suggested (Figure 1).

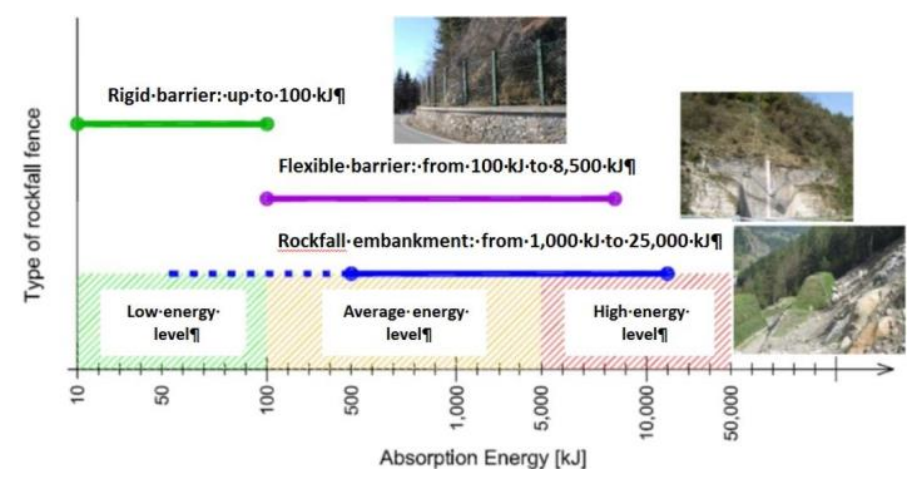

Figure 1 Correlation between the energy level and the type of rockfall barriers 
Flexible barriers are able to stop blocks with medium-high energy levels (up to 8,600 kJ), thanks to their capacity to deform. The elongation of the barrier (or fence) allows increase of the arresting time of the block $(\Delta t)$ and consequently reducing the forces $(F)$ acting against the structure (Equation (1)).

$$
\mathrm{F}=\mathrm{m} \Delta \mathrm{v} / \Delta \mathrm{t}
$$

where:

$\mathrm{F}=$ force acting against the fence after the impact.

$\mathrm{m}=$ mass of the block.

$v$ = velocity of the block.

$\mathrm{t}=$ arresting time of the block (for rigid barrier almost nil, for deformable fence approx. 0.15-0.40 s).

A high energy absorption barrier is one of the most common measures against rockfalls. It is installed at a certain distance from the detachment area. In agreement with the definition stated in the ETAG 027 (EOTA 2008), a deformable rockfall barrier is a kit of different components, which must be able to stop a block impacting against it. The kit is composed of several elements (Figure 2):

- An interception structure, generally a steel net.

- A support structure, steel posts.

- Connection elements, such as:

○ Upper longitudinal cable.

○ Lower longitudinal cable.

- Upslope bracing cable - if any.

- Lateral bracing cable.

- Energy dissipator devices (brakes) etc.

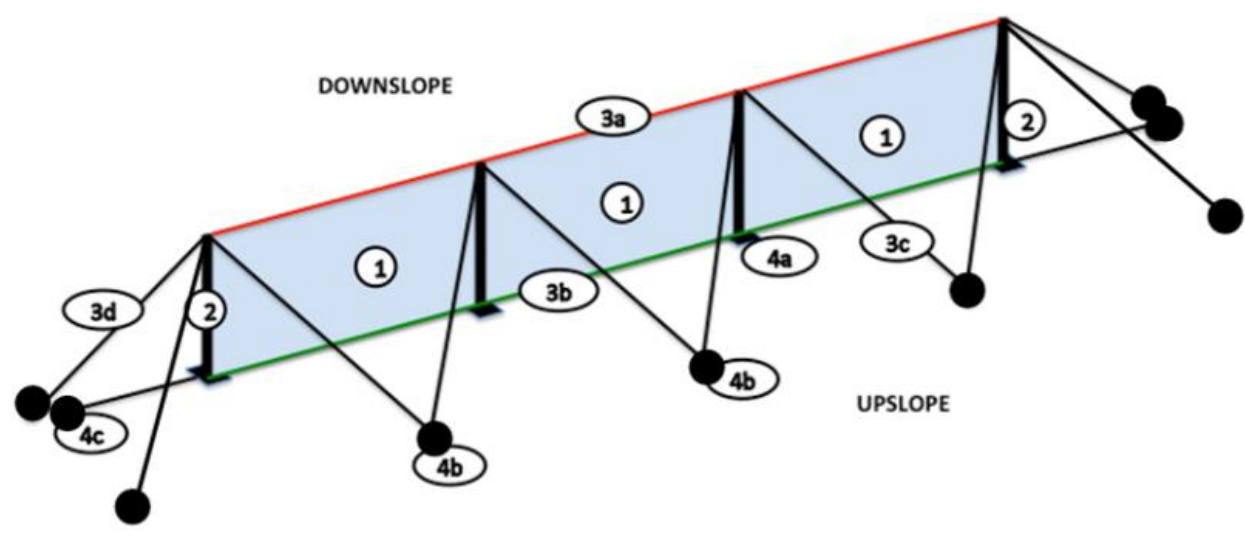

Figure 2 Components of a rockfall barrier

The structure is fixed to the soil/rock by anchoring systems. These elements transfer the forces developed from the impact to the ground (Figure 2: anchoring system of posts (4a), lateral bracing cables (4b), and upslope bracing cables (4c) - if any). It must be clarified that, as per ETAG 027 (EOTA 2008), the anchoring systems are not part of the kit. The type and the length of these components may change depending on the site characteristics, for instance rockfall fences are never installed in the same type of soil (i.e. rock, loose soil, concrete etc.). Thus, these elements cannot be standardised like the elevation part of the fence. 


\section{$2 \quad$ ETAG 027}

In order to understand and to be able to compare the behaviour of rockfall barriers, the European Organisation for Technical Approval (EOTA) issued in 2008 the ETAG 027. Even though there are other guidelines available worldwide (e.g. AASHTO 2003; WSL 2001), the European one is the strictest. Nowadays, this guideline is essentially the only test and construction framework utilised by manufacturers. ETAG 27 (and the related European Technical Approval (ETA) and European Conformity (CE) marking) represents a milestone for the rockfall barrier market, because it gives the possibility to compare the performances of different fences and it ensures the quality of the certified product.

\subsection{Crash test}

ETAG 027 has standardised all the procedures required to carry out the full-scale crash tests. It defines:

- Shape, minimum dimensions and density of the tested block.

- Dimensions of the tested barrier: it must have at least three functional modules (three spans).

- Impact features: the block must impact the barrier in the centre of the middle span.

- Minimum impact velocity of the block: no lower than $25 \mathrm{~m} / \mathrm{s}$ (approx. $90 \mathrm{~km} / \mathrm{h}$ ).

- Test field has to be able to accelerate the tested block to the minimum impact velocity; it can be on a vertical or inclined slope. No interference between the block and the soil are permitted before and during the impact.

- Two tests must be performed considering the maximum energy level (MEL), (i.e. 3,000 kJ) and the serviceability energy level (SEL), ( $S E L=1 / 3$ of the MEL, i.e. 1,000 $\mathrm{kJ}$ ). These two tests must be carried out on two different barriers $A$ and $B$, which present the same energy level as well as the same geometrical and mechanical characteristics.

- First launch at the MEL: on barrier A. To pass the test, the stopped block cannot touch the ground before the barrier reaches its maximum elongation (Figure 3 ).

- Second launch at the SEL: on barrier B.

- Third launch at SEL: again on barrier B. This launch must be done on the same barrier of $B$. No repairs are allowed between the two consecutive tests. Moreover, the 2 nd launch can be carried out only if the residual height (Figure 3 ) of the barrier, previously crashed by the first SEL impact, measures at least $70 \%$ of the nominal height of the tested fence (before the impact). During this second SEL launch the barrier simply has to withstand the falling block.

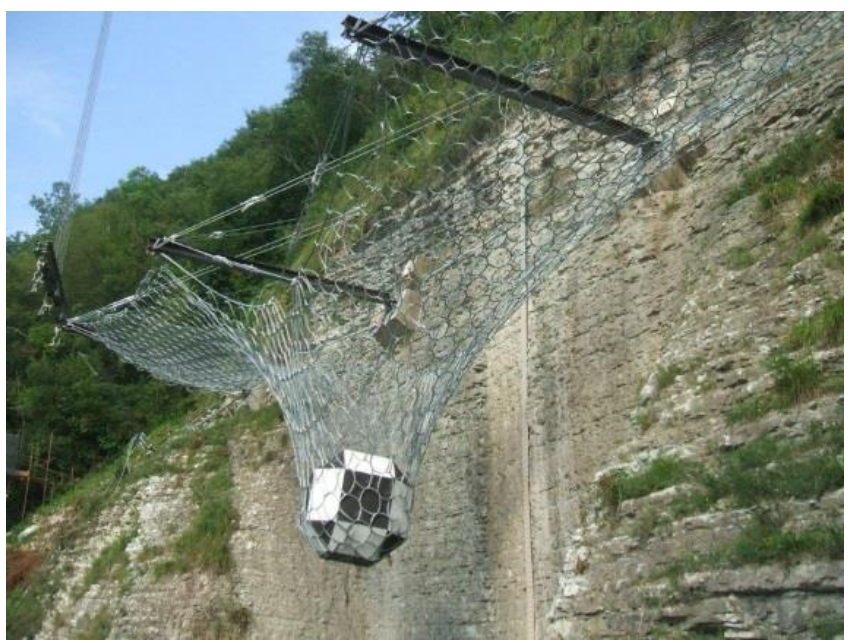

Figure 3 Deformable rockfall barrier tested at the Maximum Energy Level (MEL $=8,600 \mathrm{~kJ}$ ) according to ETAG 027 


\subsection{Test measurement}

In order to ensure uniform behaviour of the different tested barriers, the European guideline defines the parameter that must be measured during the SEL and MEL test. In this way, the comparison between two different barriers with the same energy capacity is easy, and above all, standardised. In terms of performances, the following measurements must be done:

- Maximum dynamic elongation of the interception structure: maximum downhill deformation measured parallel to the reference slope during the impact (Figure 4).

- Residual height (hR): minimum distance between the lower and the upper longitudinal cable, measured orthogonally to the reference slope after the test and without removing the block from the interception structure. The $h R$ is expressed as a certain percentage of the nominal height of the barrier $(\mathrm{hN})$, which is the distance between the upper longitudinal cable and the connection line between the base of the posts, before the impact, and measured perpendicular to the reference slope (Figure 4).

- Forces applied on the anchoring systems.

- Photos and description of the damage that has occurred in the rockfall barrier.

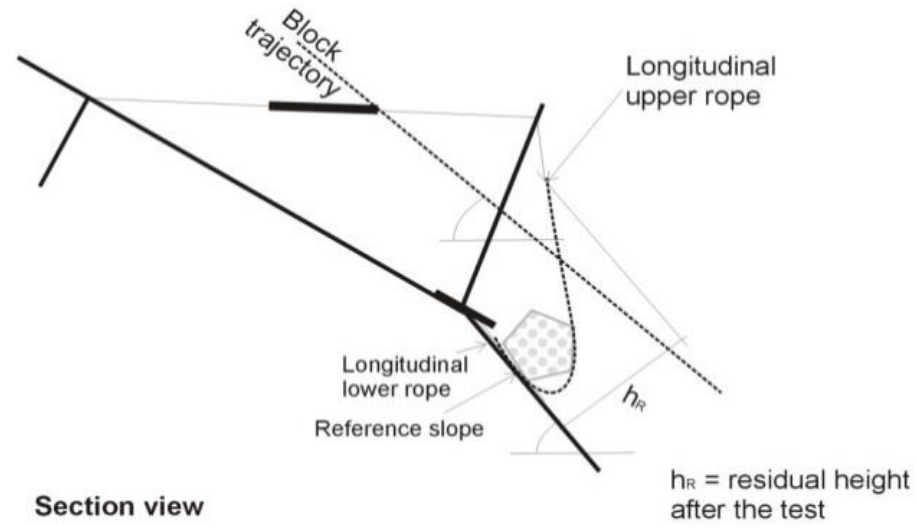

Figure 4 Measurement of the dynamic elongation and the residual height of the barrier, after the impact

ETAG 027 (EOTA 2008) classifies the barriers into three categories, based on the residual height: when $h_{R} \geq 50 \%$ of the nominal height $\left(h_{N}\right)$, the fence is classified in Category $A$; if $30 \% h_{N}<h_{R}<50 \% h_{N}$, the barrier is in Category $B$; and if $h_{R} \leq 30 \% h_{N}$ the barrier is in Category C.

\subsection{Barrier comparison}

ETAG 027 (EOTA 2008) does not define how the different components of the tested system must be manufactured and/or assembled, but it ensures that the entire tested kit is fit for stopping an impact of a block that develops a certain energy level (i.e. 3,000 kJ). In this way, comparing the performances of different structures (from different producers) with the same nominal energy capacity is quick and easy. For instance, it is possible to compare two or more different 5,000 kJ barriers, analysing the most important parameters to be considered during the design: maximum dynamic elongation, residual height, lateral gaps and efforts transmitted from the structure to the anchoring systems during the impact. In these terms, manufacturers implement their rockfall barriers in order to satisfy the minimal requirements of ETAG 027 (logic of the technology), as well as the economic aspects (market needs). The consequent result is that fences are pushed to their proper limits. Therefore, their margin of safety might be reduced. For example, a deformable rockfall barrier able to withstand an impact of 5,000 kJ, theoretically, could fail a test at 5,001 kJ.

This logic has several consequences:

- Producers are encouraged to develop cost-effective structures, by reducing the materials cost (economic reason) and increasing the performances (safety reason). 
- Designers may easily know the resistance limits of the barriers available on the market. In fact, before ETAG 027, the real performances of rockfall fences were pretty much unknown.

- The problem of the safety margin of the barrier is transferred to designers, who must introduce new design approaches to choose the right nominal capacity of the designed fence.

- All the fundamental performances are recorded and demonstrated by the full-scale tests. Any declaration of higher safety margin (or better performance) must be validated in accordance with the guideline. Without the ETA certification, issued by an EOTA member after the crash test, manufactures are not able to declare any performance of their barrier.

- The kit is comprised of elements of various sizes and configurations, depending on the required energy capacity and manufacturer. The combination of these elements does not necessarily mean that a structure with heavier (oversized) components has a higher performance capacity than one which is made up of lighter parts, but is assembled more efficiently.

From Table 1, it is possible to highlight that there is not any correlation between the dimension of the structure (dimension of the post) and its performance. As shown, the second lightest barrier (manufacturer 1) has the best performance in terms of both residual height and dynamic elongation. While, the manufacturer with the biggest structure (manufacturer 2 ) has a good residual height, but its elongation is approximately $35 \%(2.0 \mathrm{~m})$ more than the shortest one available on the market. This fact can be correlated to the assembling procedure of the components of the kit and on the efficiency of the braking elements of the fence. Both these characteristics differ between the producers.

Table 1 Comparison between four 5,000 kJ fences produced by different manufactures. The values reported are extracted by the ETA and are referred to as MEL tests: maximum deformation, residual height, and weight of the posts (steel beam)

\begin{tabular}{cccc}
\hline Manufacturer & Max elongation & $\begin{array}{c}\text { Residual height }\left(h_{R}\right) \text { and } \\
\text { category }\end{array}$ & $\begin{array}{c}\text { Beam } \\
\text { weight }^{\mathbf{3}}\end{array}$ \\
\hline Manufacturer 1 & $6.50 \mathrm{~m}$ & $70 \%$ of $\mathrm{h}_{\mathrm{N}}{ }^{4}$. Category A & $50.5 \mathrm{~kg} / \mathrm{m}$ \\
Manufacturer 2 & $8.62 \mathrm{~m}$ & $65 \%$ of $\mathrm{h}_{\mathrm{N}}{ }^{4}$. Category A & $155 \mathrm{~kg} / \mathrm{m}$ \\
Manufacturer 3 & $8.15 \mathrm{~m}$ & $61 \%$ of $\mathrm{h}_{\mathrm{N}}{ }^{4}$. Category A & $88.6 \mathrm{~kg} / \mathrm{m}$ \\
Manufacturer 4 & $12.30 \mathrm{~m}$ & $34 \%$ of $\mathrm{h}_{\mathrm{N}}{ }^{4}$. Category B & $39 \mathrm{~kg} / \mathrm{m}$ \\
\hline
\end{tabular}

${ }^{1}$ Measured considering the dynamic condition. ${ }^{2}$ Category according to ETAG $027 .{ }^{3}$ Referred to the weight of the beam, which constitutes the post (without any added elements, plate, welded components etc.). If the fence has more than one type of post, the values in Table 1 define the heaviest one. ${ }^{4} h_{N}$ is the nominal height of the fence (all the manufacturers listed above tested their barrier with $h_{N}=6.0 \mathrm{~m}$ ).

\section{$2.4 \quad$ Residual height}

ETAG 027 (EOTA 2008) defines the residual height $\left(h_{R}\right)$ as the minimum distance between the lower and the upper longitudinal cable, measured orthogonally to the reference slope after the test and without removing the block from the interception structure (Figure 5). To guarantee a high safety level of the protected area it is mandatory to use a rockfall barrier with the highest residual height. In this way, if the barrier is impacted by a block, the height of the interception structure does not change. Thus, the probability that other falling blocks jump above the impacted barrier can be reduced. 


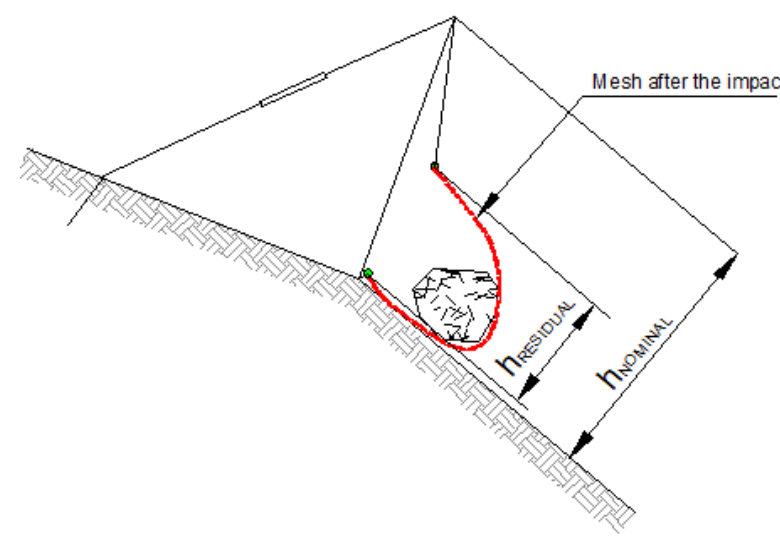

(a)

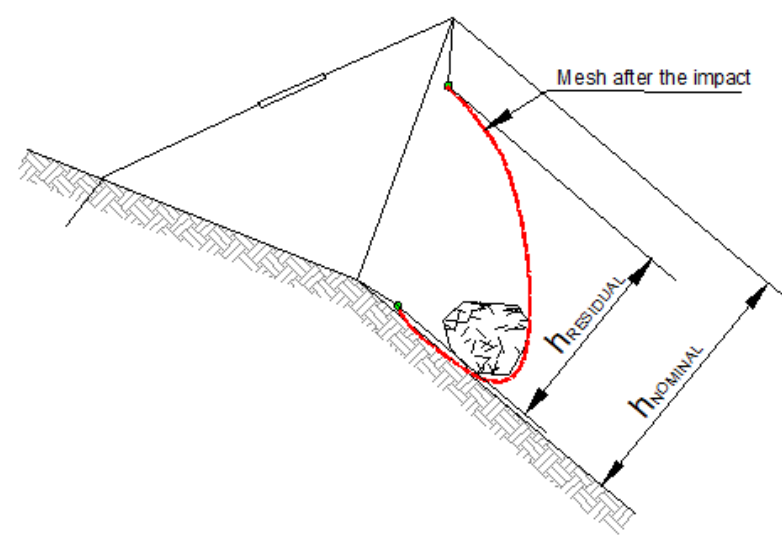

(b)

Figure 5 The advantage of having a high residual height of the barrier: (a) barrier with a residual height $>50 \%$; and, (b) barrier with a residual height $=75 \%$. Both are classified in Category A (according to ETAG 027/2008), but the second barrier has a higher safety margin if impacted by a second block

The analysis of multiple impacts can be done by comparing the probabilistic distribution of the height of the trajectories with the residual height of the barrier chosen in the design. The following graph explains how this analysis may be carried out. The specific example (Figure 6) shows that, after the first impact, the reliability of the simulation drops from 95 to $70 \%$ of the bounce height on the slope. This means that the allowable probability increases from 5 to $30 \%$.

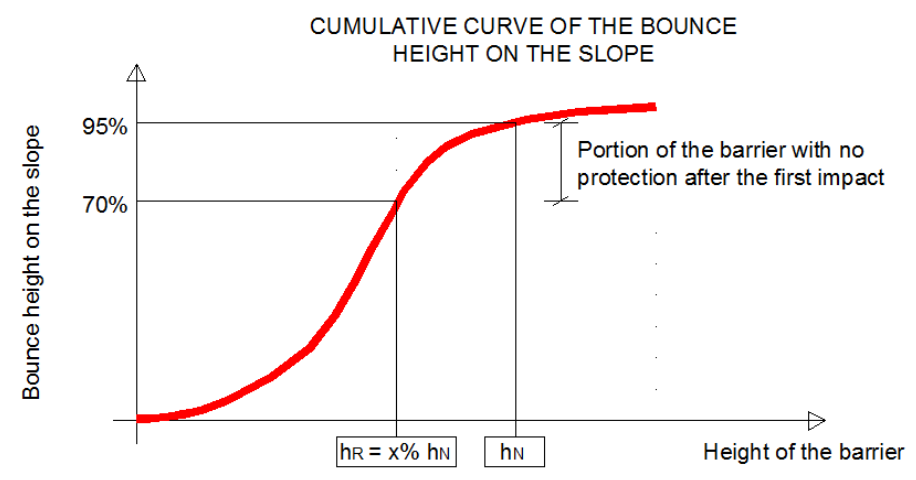

Figure 6 Example of the reduction of the safety level of the barrier after the first impact

\subsection{Dynamic elongation}

The maximum dynamic elongation of the fence plays an important role too during the design process. Barriers with a small deformation can be placed closest to the structure to be protected. This is a big advantage in the sites where the space available or the accesses to the slope are restricted. For instance, considering Table 1, the 5,000 kJ barrier produced by manufacturer 1 is suggested in all these situations where the distance between the fence and the protected area is limited.

\section{$3 \quad$ Design according to UNI 11211:4}

\subsection{Rockfall simulations}

As the basis of rockfall barrier designs, rockfall simulations must be performed in order to define the trajectories of the potential unstable blocks along the slope. The aim of these analyses is defining, in every point of the slope, the statistical distributions of energy, velocity, height of the bounces and end points of the falling masses. The input data necessary for the rockfall trajectory analyses are defined based 
on: geomechanical surveys, in order to characterise the unstable area and identify the number and the dimensions of the potential falling blocks; geological surveys, in order to identify the different soil present on the slope; and finally topography surveys, in order to identify the geometry of the study area and the exact location of the unstable rocks.

Rockfall simulations are generally performed with commercial software packages (i.e. RocFall, CRSP, Rock falls 3D), which may use different calculation approaches which may use different calculation approaches, such as lumped mass analysis (LMA) which is currently being used extensively. For a lumped mass model, the normal coefficient of restitution (Rn: parameter that depends on the material property of the soil, and it ranges between 0.1 and 0.2 ) and tangential coefficient of friction resistance (Rt: experimental parameter that depends on the slope material and the vegetation, and it ranges between 0.5 and 1.0) must be defined. Moreover, the rock is considered to be dimensionless point mass. Nowadays, new methods have been implemented to offer a more realistic behaviour of the falling blocks. For example, the rigid body impact mechanics model introduces the effect of the size and shape of the rock and its interaction with the slope. It uses the soil material parameters Rn, Rt, dynamic friction coefficient ( $\mu$ : tangent of the friction angle, obtained with experimental data) and the rolling friction (Chai et al. 2013).

Irrespective of the model used during the analysis, in order to have reliable results, rockfall simulation must consider at least 1,000+ trajectories (Giani 1997; UNI 2012). Moreover, back analyses are always recommended to validate the input data used on the simulation: the statistical distribution of the end-points (defined with the simulation) should match the real distribution of the block onsite. As shown in Figure 7, from the back analysis it is possible to define the statistical distribution of the end-points recorded onsite. For instance, in that specific case $15 \%$ of the blocks stopped in the first $20 \mathrm{~m}$ from the detachment area, $60 \%$ in the next $30-40 \mathrm{~m}, 20 \%$ in the following $150-200 \mathrm{~m}$, and only 10 blocks (approx. 5\%) reached the highway downslope.

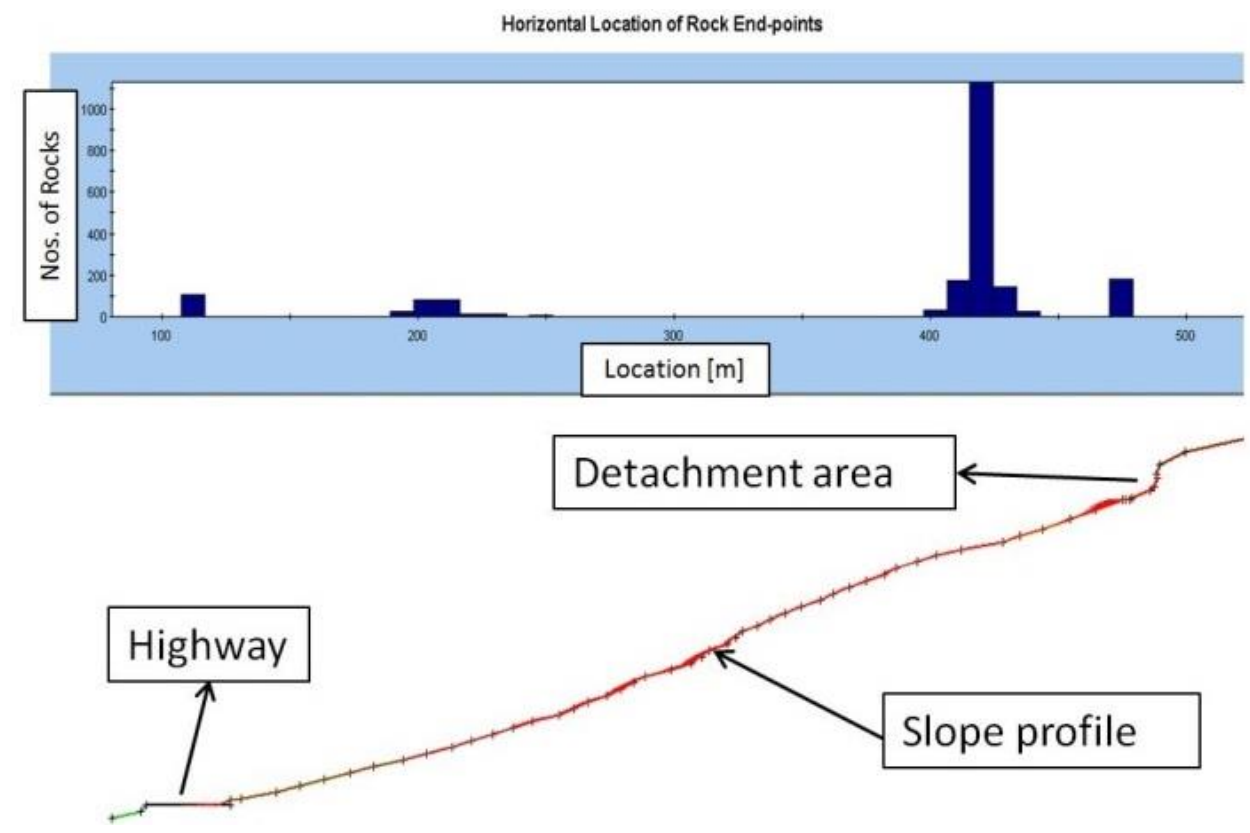

Figure 7 Example of back analysis. Statistical distribution of the horizontal location of the rock end-points; Y-Axis: number of rocks; X-Axis: location in metres (RocFall rel. 4.050)

\subsection{Installation aspects}

The simplest and easiest way to design a deformable rockfall barrier involves comparison of the energy level calculated during the rockfall simulation analysis with the results obtained by the full-scale crash tests ETAG 027 (EOTA 2008). For example, if the numerical rockfall trajectory analysis shows energy equal to $1,850 \mathrm{~kJ}$ in the location where the barrier has to be placed, therefore an ETAG 027 certified barrier able to withstand more than $1,850 \mathrm{~kJ}$ (i.e. $2,000 \mathrm{~kJ}$ ) must to be chosen. Moreover, if the height of the rock bounces 
defined with the simulation is $3.8 \mathrm{~m}$, the chosen barrier must be higher than that value (i.e. $4.0 \mathrm{~m}$ ). Finally, the distance between the fence and the protected area must be greater than the maximum dynamic elongation of the fence (i.e. according to Table 1, >6.50 $\mathrm{m}$ if the chosen barrier belongs to manufacturer 1 ). Unfortunately, this simplified calculation approach presents a lot of uncertainty related to the reliability of the input data used for the simulation, to several installation issues and, above all, to the differences between the layout of the tested barrier and the barrier installed on the field.

Designers must know that the crash tests are performed in ideal conditions, which are completely different from the in situ one. Some of the main characteristics of the tested barrier are presented below:

- Length $30 \mathrm{~m}$ : only three spans (functional modules) compose the fence.

- Impact in the centre of the barrier.

- Only one block impacts the barrier at the MEL, and two at the SEL.

- No planimetric deviations.

- No difference between the levels of the posts.

In reality (in situ), the facility configuration never occurs, in fact:

- The length of the barrier can vary from 10 to $100+\mathrm{m}$ (suggested length $70-80 \mathrm{~m}$ ).

- The fence can be impacted at any point (on the top rope, on the post, on the lateral span etc.).

- Multiple blocks (with different energy levels) may hit the structure: multiple impacts constitute one of the most severe conditions for a barrier, especially when they involve two or more functional modules.

- Planimetric distortions are frequently remarked onsite: larger deformations may occur if the deviation of the barrier presents upslope convexity, the barrier may tilt uphill.

- Differences in post elevations may modify the barrier behaviour, because anomalous stress conditions may be induced: low stresses occur on the smallest diagonal of the functional module, and high stress are on the longest one.

- Differences in the post inclination may occur for irregular slope morphologies.

\subsection{Design at limit states}

Since the full-scale crash tests are not able to describe the barrier behaviour for all the real impact conditions, the test must be considered as an index test. Therefore, the rated energy capacity of the fence must be considered nominal.

In order to study the real behaviour and define the technological limits of their fences, some manufacturers perform full-scale crash tests, according to ETAG 027 (EOTA 2008), (modifying some of the requirements described in the guideline. For example, tests with only two functional modules, or with multiple impacts, or impacted on the posts etc. have been carried out. Unfortunately, all these tests are extremely expensive (USD 50,000-100,000 each) and it is almost impossible to describe all the potential configurations that may happen in real cases. For these reasons, in January 2012 the Italian Organization for Standardization, Ente Nazionale di Unificazione (UNI) issued the UNI 11211:4 (UNI 2012), which contains the methodology to design passive rockfall fences using the Limit State Design approach.

According to the UNI 11211:4, the design of a rockfall barrier can be done considering the ultimate limit state approach or the serviceability limit state approach. In both cases, the limit state design approach introduces some partial coefficient: load coefficients, which increase the driving actions on the barrier, and reduction coefficients, which reduce the resistance of the structure. 


\subsubsection{Energy of the barrier}

The basic equation of this new design approach is:

$$
E_{s d}<E_{\text {BARRIER }} / \gamma_{E}
$$

where: $E_{\text {sd }}$ is the design energy level developed by the block against the barrier; $E_{\text {BARRIER }}$ is the energy absorbed by the barrier, as defined with the crash test carried out according to ETAG 027 (MEL or SEL); and $\gamma_{E}$ is the safety coefficient related to the energy level adopted during the design and the length of the barrier (Table 2).

Table 2 Values of the partial coefficients, according to UNI 11211:4-2012 and authors' experience

\begin{tabular}{|c|c|c|}
\hline Symbol & Notes & Value \\
\hline \multirow[t]{4}{*}{$\gamma_{\mathrm{E}}$} & SEL approach & 1.00 \\
\hline & MEL approach and fence with more than 3 spans & 1.20 \\
\hline & $\begin{array}{l}\text { MEL approach and fence with more than } 3 \text { spans } \\
\text { (where } 2 \text { parallel barrier is placed) }\end{array}$ & 1.20 \\
\hline & $\begin{array}{l}\text { MEL approach and fence with more than } 3 \text { spans } \\
\text { (where only } 1 \text { barrier is placed) }\end{array}$ & 2.00 \\
\hline \multirow[t]{4}{*}{$\gamma_{R}$} & Place rarely frequented, with low value and easy to be repaired & 1.00 \\
\hline & Place rarely frequented, with medium value and easy to be repair & 1.05 \\
\hline & Place frequented, with high value and difficult to be repaired & 1.10 \\
\hline & $\begin{array}{l}\text { Place highly frequented, with really high value }- \text { or strategic - and } \\
\text { impossible to be repaired (i.e. hospital, school etc.) }\end{array}$ & 1.20 \\
\hline \multirow[t]{2}{*}{ YVoL } & High accuracy survey to define the dimension of the blocks & 1.02 \\
\hline & Without any survey & 1.10 \\
\hline$\gamma_{\gamma}$ & Generally suggested & 1.00 \\
\hline \multirow[t]{2}{*}{$\nu_{T r}$} & Rockfall simulation based on back analysis & 1.02 \\
\hline & Rockfall simulation based on literature & 1.10 \\
\hline \multirow[t]{2}{*}{$Y_{D P}$} & High accuracy of the topographic survey & 1.02 \\
\hline & Low accuracy of the topographic discretisation & 1.10 \\
\hline \multirow[t]{2}{*}{$\gamma_{\mathrm{Rb}}$} & Suggested by UNI 11211:4-2012 & 1.00 \\
\hline & Generally suggested by authors & YVoL \\
\hline \multirow[t]{4}{*}{$\gamma_{d}$} & SEL approach & 1.00 \\
\hline & MEL approach and fence with more than 3 spans & 1.30 \\
\hline & MEL approach and fence with less than 3 spans & 1.50 \\
\hline & MEL approach and possible trajectories impacting the lateral spans & 1.50 \\
\hline
\end{tabular}

$E_{s d}$ is defined with the classical formula of the kinetic energy multiplied by a safety coefficient $\gamma_{R}$ (Table 2), which considers the human risk. In the formula the spin effect of the falling rock can be neglected, because it has been highlighted (Arndt et al. 2009) that this value is only $10-15 \%$ of the total energy; therefore it can be compensated by the introduced partial safety coefficients. 


$$
E_{s d}=\left(1 / 2 M_{d} v_{d 2}\right) \gamma_{R}
$$

where: $M_{d}$ is the design mass of the block; and $v_{d}$ is the design velocity of the block.

Designers must define the design mass and velocity as follows:

$$
\begin{gathered}
M_{d}=\left(V_{o} I_{B} \cdot \gamma\right) \cdot \gamma_{V O L} \cdot \gamma_{V} \\
v_{d}=v_{t} \cdot \gamma_{T r} \cdot \gamma_{D p}
\end{gathered}
$$

where: $\mathrm{Vol}_{B}$ is the volume of the design block; $\gamma$ is the unit weight of the rock; $\gamma_{\mathrm{Vot}}$ is the safety coefficient related to the precision of the geomechanical survey to define the size of the block (Table 2); $\nu_{\gamma}$ is the safety coefficient related to the evaluation of the unit weight of the rock (Table 2); $v_{t}$ is the velocity calculated with the rockfall simulation and considering the 95th percentile of the velocities; $\nu_{\operatorname{Tr}}$ is the safety coefficient related to the reliability of the rockfall simulation (Table 2); and $\gamma_{D p}$ is the safety coefficient related to the quality of the topographic survey (Table 2).

\subsubsection{Height of the barrier}

The minimum height of the barrier has to be defined considering the design height $\left(H_{d}\right)$ plus an upper free border, where the block cannot impact $\left(f_{\min }\right)$.

$$
H_{\text {tot }} \geq H_{d}+f_{\text {min }}=\left(H_{t} \cdot \gamma_{T r} \cdot \gamma_{D p}+R_{\text {block }} \cdot \gamma_{R b}\right)+f_{\text {min }}
$$

where: $H_{\text {tot }}$ is the nominal height of the tested barrier according to ETAG 027 (EOTA 2008); $H_{d}$ is the design height of the trajectories; $f_{\min }$ is the safety zone (upper free border) that cannot be impacted (usually $f_{\min }$ $\geq 50 \mathrm{~cm}$ ); $\mathrm{H}_{\mathrm{t}}$ is the height of the trajectories defined with the numerical simulations and considering the 95th percentile of the heights; $R_{\text {block }}$ is the average radius of the design block; and $\gamma_{\mathrm{Rb}}$ is the safety coefficient on the radius of the block (Table 2 ).

\subsubsection{Distance between the barrier and protected zone}

The minimum distance between the barrier and the protected area (DA) is determined as follows:

$$
D_{A} \geq D_{b} \cdot \gamma_{d}
$$

where: $D_{b}$ is the maximum dynamic deformation of the barrier, measured after the crash test at the MEL; $\gamma_{d}$ is the safety coefficient related to the energy level adopted during the design, the length of the barrier and the barrier-span impacted by the boulder (Table 2).

\subsection{Field installation experiences}

When choosing a rockfall barrier, the priority must be focused on the performances of the barrier, as described in the previous sections (fences with high residual height and low deformation must be preferred). However, the installation aspects ought to be taken into consideration as well as the global cost of the intervention.

While designing rockfall barriers, consultants usually do not think about the installation. Nevertheless, during the design phases it must be clear that these structures are generally installed in remote areas, characterised by very steep slopes, limited access, and where powerful machinery cannot operate. Indeed, in order to facilitate the installation, helicopters are normally used to transport the different components of the barrier: anchors, cables, nets and posts. Additionally, in these zones workers are often exposed to rockfall hazards, so it is often mandatory to operate as quickly as possible.

In order to reduce the installation issues, several manufacturers have developed their barriers to include features that make the installation faster, easier and safer by reducing the time onsite. For example, some of the major features adopted by producers are steps on the posts, to simplify the access at the top of the structure; support struts (Figure 8), to facilitate the elevation of the post and maintain the post in the proper position without fixing the bracing cables; interception structure directly connected to the 
longitudinal cables and/or posts, in order to reduce the installation time of the net; light brakes directly included on the ropes, to reduce the number of connection elements to apply on site etc.

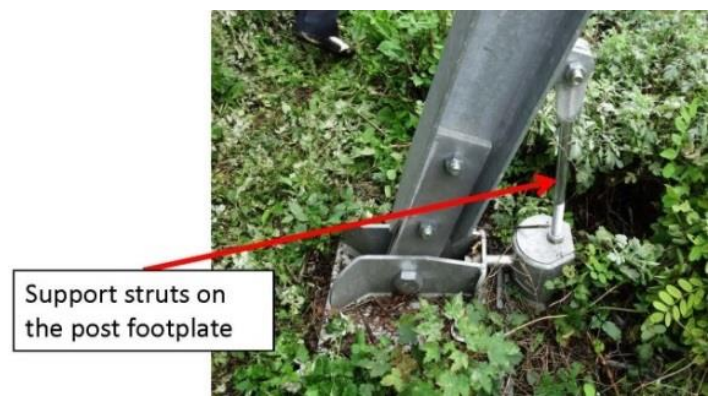

Figure 8 Example of devices to help the installation: support struts on post footplate

One of the most critical operations during the barrier installation is the positioning of the posts on the footplate. This procedure is normally realised using cranes or helicopters (Figure 9), which have limits due to the maximum allowable load. If heavy post are used (weight $>500 \mathrm{~kg}$ ) installation problems can occur especially when the weather condition are not favourable (wind).

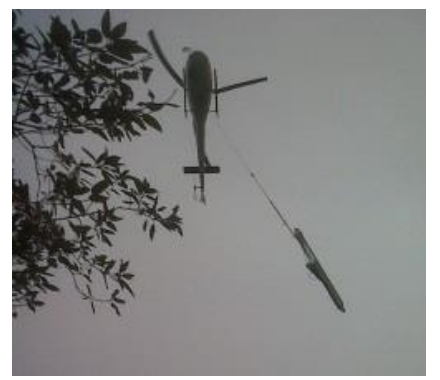

Figure 9 Installation of the barrier post using helicopters

For economic reasons, a lot of contractors prefer to use barriers with light posts, which are easier and safer to put in place compared to those barriers with large and heavy beams. Moreover, light structures allow using small helicopters, which are cheaper and easier to manoeuvre.

As previously discussed, and as reported in Table 1, it has been clarified that light rockfall barriers are not necessarily less performing than fences with oversized components, e.g. posts, cables etc. In fact, light structures cannot be considered less safe or robust than other overdesigned structures.

As an example, it is possible to compare two $5,000 \mathrm{~kJ}$ barriers produced by two different manufacturers: manufacturer 1 and 2 (see Table 1). Considering the standard height of a 5,000 kJ, which is generally 6.0 to $7.0 \mathrm{~m}$, it is possible to highlight the different total weight of the beams of these two fences. For manufacturer 1, the total weight of the beam is 303 to $353.5 \mathrm{~kg}$, while for manufacturer two it is 930 to $1,085 \mathrm{~kg}$. This remarkable difference (more than three times) may increase the installation problems onsite for the heavier fence. Moreover, in this specific case, the performances (according to ETAG 027 (EOTA 2008)) of the barrier produced by manufacturer 1 are higher than the ones of manufacturer 2 . This aspect confirms the fact that big structures may be weaker, with poorer performance than smaller one.

\subsection{Design of the anchoring system}

During the full-scale tests, manufacturers have to measure the forces transmitted to the foundations during the impact. Usually the systems to measure the forces on the foundations consist of a data logger connected to different load cells installed on all the main foundations of the barriers: post bases, upslope cables and lateral cables. Even if ETAG 027 (EOTA 2008) requires that foundations forces must be measured during the full-scale tests, the guideline does not define the foundations of the barrier as a component of the rockfall kit. The reason is due to the fact that barriers are never installed in the same type of soil (loose soil, rock etc.), thus every barrier should have its proper anchoring system. 
Barrier foundations should be designed considering the forces directly measured or calculated by the crash test. Foundations must be designed taking into account the forces transmitted to the structure during the MEL impact (for both the serviceability and ultimate limit state design), (Table 3), the geotechnical parameters of the ground and the national standards.

Table 3 Values of the forces acting on a 8,600 kJ (RMC 850/A) fence during the MEL crash test. Designers should consider these loads for their designs

\begin{tabular}{|c|cc|}
\hline Type of anchoring system & Notes & Value \\
\hline Post & $626 \mathrm{kN}$ & Compression \\
\hline Upslope bracing cable & $436 \mathrm{kN}$ & Shear \\
\hline Lateral bracing cable & $392 \mathrm{kN}$ & Pull-out \\
\hline
\end{tabular}

The anchoring systems of the rockfall barriers can be divided into two categories:

- Bracing cable anchors (lateral and upslope, if any): the pull-out forces act on this anchoring system. Usually double-leg cable anchors are used. They perform very well due to their flexibility and capacity to follow the direction of the pull-out force, which are never aligned in the direction of the anchor. For soils difficult to drill, other solutions may be adopted (e.g. self-drilling hollow bars).

- Post anchors generally consist of steel bars and/or micropiles, depending on the type of soil. They have to contrast the compression and shear forces transmitted by the structure.

The anchor systems are considered passive, because they start to work only if they are stressed by the impact; no pre-tensioning is required. They are installed in drilled-holes and they are fully grouted along their entire length in order to develop the maximum friction anchor grout and grout-soil (bond stress). The length and the diameter of the anchors, as well as the drilling diameter, depend on the design requirement.

Problems frequently arise for the post foundations, because they are usually built where heavy machineries cannot operate and where the material transportation is very difficult. In these cases, these foundations become more expensive than the barrier itself and the intervention with rockfall barriers might be rejected because it is not cost-effective. Moreover, when a severe impact strongly damages a barrier, for safety reasons, the whole structure, including the foundations, must be replaced.

Several field experiences show that when the barrier is stressed at its MEL capacity, the damages are very severe. Therefore, to re-build a new barrier is cheaper and safer than to fix the impacted one. Even if, after a large impact, the damage seems to be light or negligible, the probability of micro ruptures on cables, posts, meshes and connection components is very high. Therefore, the barrier anchors could suffer from any type of cracks, especially on the pins connecting the footplates. The opposite is the fence behaviour when hit by a SEL impact. In this case, the damage is usually small and the required maintenance is negligible. The anchoring systems usually do not suffer any damage and anchors rarely need to be replaced.

Thanks to the flexibility of the whole barrier made of steel cables and mesh, the post foundations can be designed to accept settlements. A strong concrete plinth, designed for MEL impacts, appears really redundant and not cost-effective. Moreover, the stiffness of the concrete plinth might cause issues on the fence, because the bottom of the post is not able to deform as much as the upper portion. Thus, a deformable foundation helps to dissipate energy and make the barrier safer. This concept forces structural engineers to drastically change their thought process during rockfall barriers designs. In these terms, the concrete plinths have to be thought of as aimed at getting a regular support surface and easing the installation of the footplate. Their construction should be fast and easy in any environmental condition. The plinth contribution to the bearing capacity of the footplate may be negligible. With this approach, the contribution of the foundation concrete block can be neglected and settlements should be considered acceptable even if they are larger than those usually considered acceptable for a standard building foundation. 
Steel bars are used as micropiles to transfer the loads from the base plate to the ground. These must connect the footplate to the ground directly (Figure 10). If the barrier is installed in an uneven soil, a small concrete plinth (generally $50 \times 50 \times 50 \mathrm{~cm}$ ) is suggested to give a flat base to the post. In these cases, the bars must pass throughout the small plinth in order to allow the support of the footplate and in the meantime, to make the foundation more flexible. Using flexible anchors the risk of ruptures on the footplate and of the collapse of the barrier is reduced. In this way, the rockfall fence can maintain an appreciable residual height, and consequently increase the level of safety after the first impact.

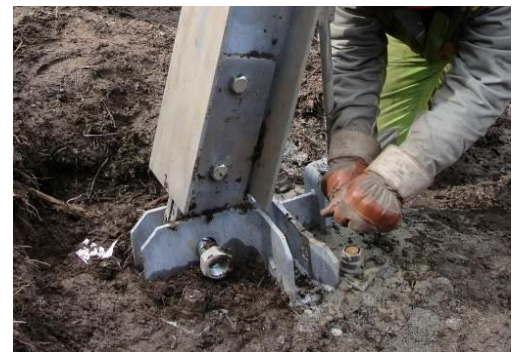

Figure 10 Example of post base systems. The base plate is installed directly on the ground

This theory was supported by several case studies analysed worldwide. Barriers with light post anchoring systems were able to withstand impacts higher than the nominal one of the fence (e.g. Figure 11: $\mathrm{km} 425$ HWY A3, Municipality of Scilla, Italy). It has been reported that the weakness of the footplate, which sunk into the ground, allowed dissipation of the energy of the impacted blocks.
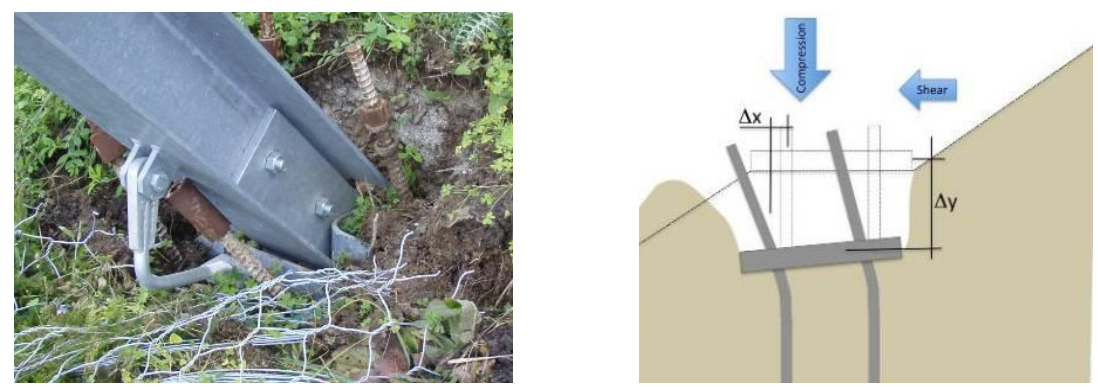

Figure 11 Settlement of the footplate after the impact. The vertical $(\Delta y=$ approximately $200 \mathrm{~mm})$ and the horizontal $(\Delta \mathrm{x}=$ approximately 50 to $100 \mathrm{~mm}$ ) displacements of the base plate represent a benefit for the energy dissipation of the fence

This concept is effective in these fences with upstream cables. In fact, the upslope bracing cables are able to transmit the stopping force from the interception structure directly to the soil, reducing the forces on the post. Furthermore, the benefit of this new design approach is to obtain cost-effective structures able to dissipate energy, increase their performance during the impact, and be easily repaired if an impact occurs.

According to the concepts highlighted in this section, it is possible to state that instead of post foundation, it would be better to talk about post base system or post anchoring system. The system should be designed, not as a massive foundation able to absorb completely all the impact forces, but as a light base that can accept deformations and displacements during the impact.

\section{Conclusion}

Rockfall barrier manufacturers test their structures in accordance to the European Guideline for Technical Approval (ETAG 027) issued in 2008 by the EOTA. Nowadays, the guideline represents a milestone for the rockfall market worldwide, because it defines a standardised methodology that manufacturers may follow to test their fences at the full-scale. Barriers that pass the full-scale test may obtain the ETA, which is an official document reporting all the performances of the barrier during the test. ETAG 027 is essentially the only test and construction framework utilised by manufacturers and presently it constitutes the base for tenders worldwide. 
The European Guideline does not define how the different components of the fence must be produced and/or assembled, but it ensures that the entire tested kit is able to stop a certain energy level. In this way, it is easier and quicker to compare all the performances of different structures, from different manufacturers, having the same nominal energy capacity.

According to ETAG 027, the tested deformable rockfall barrier must be impacted in only one specific configuration. In fact, the test-block (having predefined shape and weight) must hit the centre of the central span of the fence (composed by three spans) with a velocity no lower than $25 \mathrm{~m} / \mathrm{s}$ (approximately $90 \mathrm{~km} / \mathrm{h}$ ). Unfortunately, real in situ conditions are normally extremely different from those at the test facility: rockfall events frequently generate multiple impacts, which may stress the barrier at any point, i.e. impact on the post, lateral span, upper longitudinal cable etc. Therefore, the design of these types of structures is really difficult and complex.

The simplest and easiest way to design a rockfall barrier involves comparing the energy level calculated during the rockfall simulation analysis with the results obtained during the crash-tests. This calculation approach presents a lot of uncertainties related to: the reliability of the input data used for the simulation, several installation issues, as well as the differences between the configuration and the performances of the tested and the installed fence. To consider all the technical limits of the installed structures, a new design approach was introduced with the Italian Standard UNI 11211:4 (UNI 2012), which introduces the concept of the ultimate and serviceability limit states. The forces acting on the fence are increased by partial load coefficients, while the resisting capacity of the fence is decreased by partial reduction coefficients. These coefficients allow estimating the required energy capacity and the height of the fence, as well as its minimum distance from the protected area.

Moreover, during the design, the location of where the rockfall fences will be built must be known: often remote areas characterised by very steep slopes, limited accesses, and where powerful machinery cannot operate. Additionally, in these zones, workers are frequently exposed to rockfall hazards. Thus, light barriers, simple to install and with modest anchoring systems, are preferred to heavy and complex fences, founded on large concrete plinths. This paper clarified that light rockfall barriers do not necessarily provide poorer performance than those with oversized components. In fact, crash-test results and real impacts show that some of the lightest barriers available on the market may offer lower elongations and higher residual heights.

Even if the anchoring systems of the rockfall fence are not considered part of the tested kit, according to ETAG 027 (EOTA 2008), these elements are really important for the global behaviour of the barrier. In fact, they must be able to dissipate the energy themselves, in order to reduce the damage to the fence during an impact, as well as reduce the maintenance costs. Therefore, light anchoring systems that may accept deformations and settlements are preferred to massive foundations able to totally absorb the forces transmitted during the impact.

\section{References}

AASHTO (American Association of State Highway and Transportation Officials) 2003, Recommended procedures for the testing of rock-fall, standing committee on highways, prepared by JD Higgins.

Arndt, B, Ortiz, T \& Turner, AK 2009, 'Colorado's full-scale field testing of rockfall attenuator systems', Transportation Research Circular E-C141, prepared for the Transportation Research Board, sponsored by the Colorado Department of Transportation (CDOT).

Chai, S, Yacoub, T, Charbonneau, K \& Curran, JJ 2013, 'The effect of rigid body impact mechanics on tangential coefficient of restitution', GeoMontreal 2013, Montreal.

EOTA (European Organisation for Technical Approval) 2008, ETAG 027: Guideline for European technical approval of falling rock protection kits, Brussels, www.eota.be

Giani, GP 1997, 'Rockfall', Hevelius Edizioni.

UNI (Ente Nazionale Italiano di Unificazion) 11211-4:2012, 'Opere di difesa dalla caduta massi'.

WSL (Swiss Federal Institute for Forest, Snow and Landscape Research) 2001, Guideline for the approval of rockfall protection kits, Swiss Agency for the Environment, Forests and Landscape, Bern, Switzerland. 